\title{
Avaliação da contagem de células somáticas na primeira lactação de vacas holandesas no dia do controle mensal
}

\section{Severino Benone Paes Barbosa1', Humberto Gonzalo Monardes², Roger lan Cue ${ }^{2}$, Newton Pohl Ribas ${ }^{3}$, Ângela Maria Vieira Batista ${ }^{4}$}

\footnotetext{
${ }^{1}$ Departamento de Zootecnia da UFRPE, Rua Dom Manoel de Medeiros s/n, Dois Irmãos - Recife, PE, CEP: 52171-900. Bolsista CAPES.

2 Departamento de Ciência Animal - McGill University, Canadá.

3 Departamento de Zootecnia - UFPR.

${ }^{4}$ Departamento de Zootecnia - UFRPE. Bolsista CNPq.
}

RESUMO - Avaliaram-se a contagem (CCS) e o escore (ECS) de células somáticas de vacas holandesas primíparas no dia do controle e a influência de causas não-genéticas sobre a presença de células somáticas no leite. Foram obtidas 172.304 amostras de leite de vacas holandesas primíparas no dia do controle, coletadas no período de jan/93 a dez/98 pelo Programa de Análises de Rebanhos Leiteiros do Paraná (PARLPR). As variáveis fixas consideradas foram região (bacia leiteira), número de ordenhas ( $2 x$ ou 3x/Nordenha), dias em lactação (5 a 450/Dialac), idade da vaca, em meses (20 a 40/Idames), mês de controle (jan. a dez./Mescon) e idade da amostra, em dias (0 a 15/Diaana). Os efeitos aleatórios foram rebanho (região), vaca e resíduo. Os dados foram analisados por REML, sob modelo misto, por meio da estrutura estatística Spatial Power [sp(pow)]. As médias não ajustadas, para CCS (x1000 cel/mL) e ECS, segundo o ano de parto, variaram de 400,245 $\pm 468,558$ e 3,55 $\pm 0,82$ (1993)

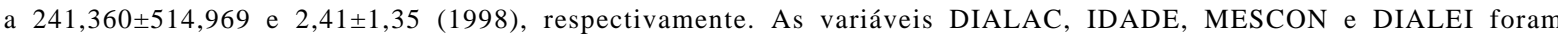
importantes fontes de variação e devem ser consideradas na avaliação da CCS e do ECS. As altas correlações fenotípicas estimadas entre dias consecutivos da produção de leite $(0,9591$ a 0,9653 , para CCS, e 0,9632 e 0,9813 , para ECS) permitem o estabelecimento de práticas de rotina que podem contribuir para a redução da incidência de mastite clínicas e/ou subclínica.

Palavras-chave: CCS, ECS, leite, mastite, spatial-power

\section{Evaluation of test-day somatic cell count of first lactation Holstein cows}

\begin{abstract}
Data consisting of 172,304 test-day records of first lactation Holstein cows were used to evaluate nongenetic effects on Somatic Cell Count (SCC) and Somatic Cell Score (SCS). Milk samples were collected in Holstein herds supervised by the Dairy Herd Analysis Program, at Paraná State, Brazil, between January 1983 and December 1998. The statistical models included the fixed effects of region (Reg), number of milkings (NM), days in milk (DIM), age of cow (AC), month of test-day (MTD), days of storaging of samples before analysis (DS) and the random effects of herd, cow and residual. Data was analyzed by REML using the spatial power procedure. Observed means for SCC (x1000 cel/mL) and SCS ranged from $400,245 \pm 468,558$ and $3.55 \pm 0.82$ in 1993 to $241,360 \pm 514,969$ and $2.41 \pm 1.35$ in 1998 , respectively. DIM, AC, MTD and DS effects were significant for SCC and SCS. The phenotypic correlations between SCC and SCS on consecutive test-days suggest it is possible to estabilish management routines to reduce the presence of clinical and/or subclinical mastitis in first lactation Holstein cows.
\end{abstract}

Key Words: mastitis, milk, somatic cell count, somatic cell score, spatial power

\section{Introdução}

A mastite causa sérias perdas aos produtores de leite no mundo inteiro. Entretanto, de forma mais simplificada, é definida como uma infecção intramamária causada por agentes patógenos oriundos do ambiente e do próprio animal, tornando-se a causa final do sistema e determinando as perdas do produtor, tanto pela redução na produção de leite das vacas quanto pelos gastos com medicamentos, principalmente, antibióticos, na tentativa de controle da doença
(Larry Smith et al., 1985; Larry Smith \& Hogan, 1998). Nos EUA, Bramley et al. (1996) estimaram prejuízo anual de 2 bilhões de dólares. No Brasil, essas informações são muito inconsistentes, entretanto, Costa et al. (1999), trabalhando com rebanhos leiteiros dos estados de São Paulo e Minas Gerais, estimaram perdas pela doença de US $\$ 317,93 / \mathrm{vaca} /$ ano e prejuízos de US\$20.611,32/propriedade/ano.

Visando reduzir as perdas provocadas pela mastite, alguns estudos têm sido desenvolvidos para adoção de novos modelos de manejo nos rebanhos. A contagem de 
células somáticas (CCS), que apresenta correlação positiva com a presença de mastite (Coffey et al., 1986; Emanuelson et al., 1988; Heuven et al., 1988; Pösö \& Mantysaari, 1996; Rupp \& Boichard, 1999; Rupp \& Boichard, 2000), passou a ser um dos principais métodos utilizados no controle da infecção. Portanto, a CCS passou a ser um método clássico para interpretar a saúde da glândula mamária, principalmente quanto à presença de mastite subclínica, e tem sido amplamente utilizada pelos produtores de leite de diversos países. A CCS é mais facilmente mensurada e tem estimativa de herdabilidade mais alta que a incidência de mastite; conseqüentemente, pode servir como característica substituta em programas de melhoramento genético.

O fato de a correlação genética entre CCS e mastite clínica ser menor que 1 tem definido a estratégia de utilização da CCS nos diferentes países em seus programas de melhoramento de bovinos leiteiros. Por sua alta correlação ( $\pm 70 \%)$, a CCS é suficiente para ser incluída em programas de avaliação de reprodutores. Nesse caso, os autores admitem que as características CCS e mastite são as mesmas e, portanto, a seleção direta pela redução da CCS pode reduzir, indiretamente, a incidência de mastite nos rebanhos. Entretanto, alguns estudos têm demonstrado que a utilização simultânea de ambas as características tem proporcionado melhores respostas, em comparação à seleção isolada de cada característica (Philipsson et al., 1995; Heringstad et al., 2000). O grande problema, nesse caso, é como implementar um eficiente e seguro programa de saúde que contemple a avaliação da mastite clínica.

Nos países economicamente desenvolvidos, a CCS é praticada rotineiramente e adotada na avaliação como índice no melhoramento dos rebanhos leiteiros. Apesar da importância da CCS nos programas de melhoramento e de sua larga utilização, ainda persistem questionamentos quanto à sua real aplicação, tendo em vista os valores dos parâmetros utilizados que determinam pequenos ganhos, embora permanentes.

No Brasil, os primeiros ensaios envolvendo a CCS foram realizados no Paraná. Atualmente, mais cinco estados (RS, SP, MG, GO e PE) integram a Rede Brasileira de Qualidade do Leite (RBQL) e possuem seus laboratórios de análise de leite centralizados, tornando disponível a CCS como prática de rotina no monitoramento da glândula mamária, no manejo e no melhoramento genético dos rebanhos leiteiros brasileiros.

Com base nesses princípios, este trabalho foi realizado com os seguintes objetivos: avaliar a contagem de células somáticas (CCS) e o escore de células somáticas (ECS), no dia do controle leiteiro mensal, no leite de vacas holandesas primíparas; estudar os efeitos de causas não-genéticas que possam estar influenciando a presença de células somáticas no leite dessas vacas; e estimar componentes de covariância, para efeitos aleatórios, entre dias consecutivos da produção de leite de uma mesma vaca.

\section{Material e Métodos}

Os dados utilizados neste estudo referem-se às informações zootécnicas do banco de dados do Programa de Análise de Rebanhos Leiteiros do Paraná (PARLPR), da Associação Paranaense dos Criadores de Bovinos da Raça Holandesa (APCBRH), correspondentes às produções leiteiras obtidas no dia do controle mensal (test-day) no período de janeiro/93 a dezembro/98.

A maioria das fazendas tem a pecuária leiteira como atividade principal. As propriedades situadas nas bacias leiteiras de Arapoti, Batavo, Castrolanda, Witmarsum e Clac possuem boas instalações e sistemas de alimentação tanto com volumosos (pastagens, silagens, silagens présecas de gramíneas de inverno e fenação) quanto com concentrados. De modo geral, os animais dessas fazendas apresentam bom padrão zootécnico.

Nas propriedades situadas nas bacias leiteiras localizadas em outras regiões do estado, os rebanhos selecionados são encontrados em menores proporções. As fazendas possuem menor infra-estrutura e a alimentação volumosa aos animais é baseada, principalmente, em gramíneas tropicais. A produtividade média normalmente é inferior à dos rebanhos da Região Sul.

Todas as fazendas mantêm práticas de manejo higiênico-sanitário que incluem rigoroso controle sanitário com testes intradérmicos para tuberculose e vacinações sistemáticas contra febre aftosa, brucelose, raiva, carbúnculo sintomático e pneumoenterite. Os controles de endo e ectoparasitos são realizados periodicamente segundo calendário específico.

A ordenha é, em sua totalidade, realizada por meio de ordenhadeiras mecânicas, desde o tipo mais simples, de balde ao pé, até o de salas computadorizadas. As coletas das amostras de leite foram realizadas durante os controles oficiais da APCBRH, sendo tomada uma amostra composta (ordenhas da manhã e da tarde) por vaca. O leite foi conservado com dicromato de potássio $\left(\mathrm{K}_{2} \mathrm{Cr}_{2} \mathrm{O}_{7}\right)$ e a CCS foi realizada por meio de citometria de fluxo utilizando-se o equipamento Somacount 500 (Bentley Instruments Inc.).

Foram analisados dados correspondentes a 172.304 amostras do dia do controle mensal (test-day) das primeiras lactações de vacas holandesas primíparas, obtidos no 
período de janeiro/93 a dezembro/98. Os dados foram submetidos inicialmente a uma análise descritiva para melhor consistência das informações, o que ocasionou uma série de restrições, e maior adequação às análises estatísticas.

As análises estatísticas foram desenvolvidas separadamente por ano de parto da vaca, em decorrência dos seguintes fatores: a) restrição computacional b) ano de parto - fator que aninha, naturalmente, vários outros fatores, o que, evidentemente, pode ser um caminho apropriado para a subdivisão dos dados, visto que o efeito "vacas" foi aninhado dentro de ano de parto; c) análises separadas por ano permitem avaliações empíricas sobre a variabilidade da estimação dos parâmetros, pois possibilita estimativas completamente independentes de cada um dos diferentes parâmetros.

As variáveis dependentes analisadas foram contagem de células somáticas (CCS) e escore de células somáticas (ECS). A CCS é uma aferição real da quantidade de células presentes no leite, mas, como uma medida estatística e de análise genética, apresenta algumas limitações: não tem distribuição normal e sua relação com a produção de leite não é linear. Portanto, para possibilitar análises estatísticas de melhor precisão para utilização em programas de melhoramento genético, a CCS necessita de algumas transformações matemáticas que possibilitem alcançar a normalidade e homogeneidade das variâncias (Ali \& Shook, 1980; Shook, 1982a; Shook, 1982b; Shook \& Ruegg, 1999). Dessa forma, dados de CCS foram transformados em logaritmos de base $2\left(\log _{2}\right)$, criando a variável ECS, apesar de que, em trabalho de revisão, Mrode \& Swanson (1996) sugeriram que a transformação logarítmica não influencia as estimativas dos parâmetros genéticos.

O modelo estatístico geral utilizado foi o seguinte:

$$
\begin{gathered}
\mathrm{Y}_{\mathrm{ijklmnop}}=\mu+\text { reg }_{\mathrm{i}}+\text { reb }_{\mathrm{ij}}+\operatorname{nord}_{\mathrm{k}}+\text { dialei }_{1}+\text { idames }_{\mathrm{m}} \\
+ \text { mescon }_{\mathrm{n}}+\text { diaana }_{\mathrm{o}}+\text { vaca }_{\mathrm{ijkmp}}+\mathrm{e}_{\mathrm{ijklmnop}}
\end{gathered}
$$

em que: $\mathrm{Y}_{\mathrm{ijklmnop}}=$ variável dependente $(\mathrm{CCS}$ ou ECS); $\mu=$ constante inerente a todas as observações; reg $_{\mathrm{i}}=$ efeito da i-ésima região, sendo $\mathrm{i}=1, \ldots, 7 ; \mathrm{reb}_{\mathrm{ij}}=$ efeito do j-ésimo rebanho, dentro da i-ésima região, sendo reb $_{\mathrm{ij}} \sim \mathrm{N}\left(0, \mathrm{I}^{2}{ }_{\text {reb }}\right)$; $\operatorname{nord}_{\mathrm{k}}=$ efeito do k-ésimo número de ordenhas efetuadas, sendo $\mathrm{k}=2 \mathrm{x}$ ou $3 \mathrm{x}$; dialei ${ }_{1}=$ efeito do l-ésimo dia de lactação, sendo $1=5 \leq \operatorname{dim} \leq 450$; idames ${ }_{\mathrm{m}}=$ efeito do $\mathrm{m}_{-}{ }^{- \text {ésima idade }}$ da vaca ao parto, em meses, sendo $m=20$ até $40 ;$ mescon $_{n}=$ efeito do n- ${ }^{\text {ésimo }}$ mês de controle, sendo $\mathrm{n}=1 \mathrm{a} 12$; diaana $_{\mathrm{O}}=$ efeito do o- ${ }^{-}$simo intervalo de controle, em dias, entre a coleta de leite e análise no laboratório, sendo $\mathrm{o}=0$ a 15; vaca $_{i j k m p}=$ efeito aleatório da p-ésima vaca, da i-ésima região, do j-ésimo rebanho, de k-ésimo número de ordenhas, de m-ésima idade ao parto, sendo vaca ${ }_{\mathrm{ijkmp}} \sim \mathrm{N}\left(0, \mathrm{I}^{2}{ }_{\text {vaca }}\right)$; $\mathrm{e}_{\mathrm{ijklmnop}}=$ efeito residual aleatório da $\mathrm{p}^{\text {- }}{ }^{\mathrm{sima}}$ vaca, da i- ${ }^{-}$sima região, do j-ésimo rebanho, de k-ésimo número de ordenhas, no l-ésimo dia de controle, de m-ésima idade ao parto, n-ésimo mês de controle, no o-ésimo dia de análise, sendo $e_{i j k l m n o p} \sim N(0, R) ; R=$ matriz de variância-covariância das observações do controle mensal (test day), com blocos na diagonal, cada um correspondente a uma observação por vaca.

Foram utilizadas três diferentes estruturas de covariância para estimativas dos erros (e's) e da covariância dos controles mensais da lactação: a) Compound Symmetry (CS); b) Autoregressive [ar(1)]; c) Spatial Power [sp(pow)].

As estimativas dos efeitos fixos e de variância e covariância foram obtidas por meio de Máxima Verossimilhança Restrita (REML), por processo iterativo, sob modelo misto (PROC MIXED, SAS/2000; St-Pierre, 2001). Posteriormente, realizou-se uma análise de regressão (GLM, SAS/ 2000) com as estimativas dos mínimos quadrados para CCS e ECS, considerando ano de parto como efeito fixo e dias em lactação como co-variável. Essa análise serviu para avaliar, a cada ano, o comportamento das médias dos quadrados mínimos da CCS e do ECS em relação às respectivas curvas de regressão ajustadas para todos os anos em conjunto.

\section{Resultados e Discussão}

O melhor ou mais apropriado modelo estatístico para análise dos dados, para ambas as características (CCS e ECS), foi o sp(pow), o que era esperado, pois a premissa de igual covariância entre os intervalos de teste era improvável. Como os intervalos de teste não foram sempre iguais, os outros modelos apresentaram inconsistência nas análises e não convergiram.

Na Tabela 1 são apresentadas as médias não ajustadas de CCS e ECS, segundo o ano de parto da vaca.

Nas Tabelas 2 e 3 constam os resumos das análises de variância para CCS e ECS, de acordo com os anos estudados. As variáveis dias em lactação, idade da vaca ao parto, mês de coleta e idade da amostra foram importantes fontes de variação e determinaram respostas diferenciadas da CCS e do ECS, para os diferentes anos, com exceção das duas últimas, no ano de 1996, para CCS. As variáveis região (bacia leiteira) e número de ordenhas estudadas determinaram diferentes respostas, alternando efeitos significativos e não-significativos sobre CCS e ECS ao longo dos anos.

Um dos pontos mais importantes do estudo foi avaliar o efeito dos dias em lactação ou da fase da lactação sobre a CCS e ECS. Houve efeito linear significativo $(P<0,01)$ da fase de lactação sobre a CCS, ou seja, à medida que a fase 
Tabela 1 - Médias não ajustadas da CCS e do ECS de vacas holandesas primíparas, segundo o ano de parto da vaca

Table 1 - Observed means for SCC and SCS of first lactation Holstein cows by calving year

\begin{tabular}{lccc}
\hline $\begin{array}{l}\text { Ano de parto } \\
\text { da vaca } \\
\text { Calving year }\end{array}$ & $\begin{array}{c}\text { No de } \\
\text { amostras }\end{array}$ & \multicolumn{2}{c}{$\begin{array}{c}\text { Característica } \\
\text { Trait }\end{array}$} \\
& & \multicolumn{2}{c}{ of samples } \\
\cline { 2 - 4 } & & CCS $\pm \mathrm{DP}$ & $\begin{array}{c}\mathrm{ECS} \pm \mathrm{DP} \\
S C S \pm S D\end{array}$ \\
\hline 1993 & 15225 & $400,245 \pm 468,558$ & $3,546 \pm 0,820$ \\
1994 & 33046 & $384,732 \pm 536,378$ & $3,433 \pm 0,910$ \\
1995 & 37895 & $394,173 \pm 573,170$ & $3,372 \pm 1,085$ \\
1996 & 35198 & $284,651 \pm 595,718$ & $2,650 \pm 1,313$ \\
1997 & 30597 & $279,986 \pm 591,910$ & $2,635 \pm 1,304$ \\
1998 & 17032 & $241,360 \pm 514,969$ & $2,407 \pm 1,350$ \\
\hline
\end{tabular}

CCS: $(x 1000 \mathrm{cel} / \mathrm{mL})($ SCC: $(x 1000 \mathrm{cel} / \mathrm{mL})$.

ECS: log na base 2 (SCS: $\left.\log _{2}\right)$.

de lactação avançou, houve aumento na quantidade de células somáticas presentes no leite (Figura 1). Constatou-se efeito quadrático $(\mathrm{P}<0,01)$ da fase de lactação sobre o ECS, que foi menos acentuado no início da lactação e cresceu gradualmente com o avanço da lactação (Figura 2). Estes resultados corroboram aqueles obtidos por Haile-Mariam et al. (2001), que também relataram efeito quadrático do estádio da lactação sobre o ECS em lactações de vacas Australian Dairy. Entretanto, esses autores verificaram decréscimo acentuado no ECS nos primeiros 60 dias de lactação seguido de crescimento gradual. Situações semelhantes foram descritas por Emanuelson \& Persson (1984), para lactações de vacas Swedish Red and White e Swedish Friesian, e por Kennedy et al. (1982), para lactações de vacas Holsteins. Esse aumento na quantidade de células somáticas ao final da lactação pode estar relacionado ao menor volume de leite, proporcionando maiores concentrações de células (Emanuelson \& Persson, 1984; Kennedy et al., 1982; Hortet et al., 1999) e/ou possíveis respostas à infecção (Haile-Mariam et al., 2001). De todos os resultados obtidos, o único atípico foi verificado no ano de 1995 (Figura 2), no qual as médias dos quadrados mínimos para ECS não acompanharam a curva de regressão estimada.

A idade da vaca influenciou significativamente $(\mathrm{P}<0,01)$ a CCS e o ECS (Tabelas $2 \mathrm{e} 3 \mathrm{e}$ Figura 3 ). Na Tabela 4 constam os números de amostras de acordo com a idade da vaca. Tanto para CCS quanto para ECS, houve aumento desses valores à medida que a idade da vaca avançou, entretanto, verificou-se também que as variações foram maiores a partir de 32 meses de idade. Entre as idades de 24 e 32 meses, quando houve maior concentração do número de parições, os valores de CCS e ECS foram mais estáveis. Considerando a alta associação da CCS e a incidência de mastite, é
Tabela 2 - Resumo das análises de variância para CCS segundo os efeitos fixos, de acordo com o ano de parto da vaca Table 2 - Summary of the analyses of variance for SCC by calving year of the cow

\begin{tabular}{|c|c|c|c|c|c|c|}
\hline \multirow{2}{*}{$\begin{array}{l}\text { Efeito } \\
\text { Effect }\end{array}$} & \multicolumn{2}{|c|}{93} & \multicolumn{2}{|r|}{94} & \multicolumn{2}{|r|}{95} \\
\hline & $\mathrm{gl}(d f)$ & $\mathrm{F}$ & $\mathrm{gl}(d f)$ & $\mathrm{F}$ & $\mathrm{gl}(d f$ & f) $\mathrm{F}$ \\
\hline Região (Reg) & 6 & $0,61 \mathrm{~ns}$ & 6 & $3,02 * *$ & 5 & $4,33 * *$ \\
\hline Nordenha $(N M)$ & 1 & $1,29 \mathrm{~ns}$ & 1 & $5,11 *$ & 1 & $9,13 * *$ \\
\hline Dialac (DIM) & 430 & $1,16^{*}$ & 430 & $1,71 * *$ & 395 & $1,18 * *$ \\
\hline Idames $(A C)$ & 26 & $3,24 * *$ & 27 & $1,75 * *$ & 28 & $2,20 * *$ \\
\hline Mescon (MTD) & 11 & $52,33 * *$ & 10 & $53,49 * *$ & 11 & $12,55 * *$ \\
\hline Diaana $(D S)$ & 10 & $3,61 * *$ & 15 & $2,71 * *$ & 15 & $3,15 * *$ \\
\hline
\end{tabular}

\begin{tabular}{lrcrrrr} 
& $\mathrm{gl}(d f)$ & $\mathrm{F}$ & $\mathrm{gl}(d f)$ & $\mathrm{F}$ & $\mathrm{gl}(d f)$ & $\mathrm{F}$ \\
\hline Região $($ Reg $)$ & 5 & $0,44 \mathrm{~ns}$ & 5 & $2,14 \mathrm{~ns}$ & 5 & $1,55 \mathrm{~ns}$ \\
Nordenha $(N M)$ & 1 & $0,00 \mathrm{~ns}$ & 1 & $2,32 \mathrm{~ns}$ & 1 & $1,55 \mathrm{~ns}$ \\
Dialac $(D I M)$ & 395 & $1,45 * *$ & 435 & $1,51 * *$ & 344 & $1,24 * *$ \\
Idames $(A C)$ & 27 & $5,01 * *$ & 27 & $2,86 * *$ & 28 & $3,44 * *$ \\
Mescon $(M T D)$ & 11 & $1,03 \mathrm{~ns}$ & 11 & $4,45 * *$ & 11 & $2,52 * *$ \\
Diaana $(D S)$ & 15 & $1,27 \mathrm{~ns}$ & 15 & $6,96 * *$ & 15 & $2,58 * *$
\end{tabular}

(*) $\mathrm{P}<0,05 ;\left({ }^{* *}\right) \mathrm{P}<0,01$.

Tabela 3 - Resumo das análises de variância da ECS segundo os efeitos fixos, de acordo com o ano de parto da vaca

Table 3 - Summary of the analyses of variance for SCS by calving year of the cow

\begin{tabular}{|c|c|c|c|c|c|c|}
\hline \multirow{2}{*}{$\begin{array}{l}\text { Efeito } \\
\text { Effect }\end{array}$} & \multicolumn{2}{|c|}{93} & \multicolumn{2}{|r|}{94} & \multicolumn{2}{|r|}{95} \\
\hline & $\mathrm{gl}(d f)$ & $\mathrm{F}$ & $\mathrm{gl}(d f)$ & $\mathrm{F}$ & $\mathrm{gl}(d f)$ & $\mathrm{F}$ \\
\hline Região (Reg) & 6 & $0,71 \mathrm{~ns}$ & 6 & $2,39 *$ & 5 & $1,56 \mathrm{~ns}$ \\
\hline Nordenha $(N M)$ & 1 & $0,29 \mathrm{~ns}$ & 1 & $1,85 \mathrm{~ns}$ & 1 & $20,41 * *$ \\
\hline Dialac (DIM) & 430 & $1,25 * *$ & 430 & $4,02 * *$ & 395 & $2,19 * *$ \\
\hline Idames $(A C)$ & 26 & $3,37 * *$ & 27 & $2,50 * *$ & 28 & $3,77 * *$ \\
\hline Mescon (MTD) & 11 & $225,35 * *$ & 10 & $329,20 * *$ & 112 & $42,23 * *$ \\
\hline \multirow[t]{3}{*}{ Diaana $(D S)$} & 10 & $10,23 * *$ & 15 & $8,32 * *$ & 15 & 11,32 \\
\hline & \multicolumn{2}{|c|}{96} & \multicolumn{2}{|c|}{97} & \multicolumn{2}{|c|}{98} \\
\hline & $\mathrm{gl}(d f)$ & $\mathrm{F}$ & gl $(d f)$ & $\mathrm{F}$ & $\mathrm{gl}(d f)$ & $\mathrm{F}$ \\
\hline Região (Reg) & 5 & $0,87 \mathrm{~ns}$ & 5 & $3,04 *$ & 5 & $1,53 \mathrm{~ns}$ \\
\hline Nordenha $(N M)$ & 1 & $2,08 \mathrm{~ns}$ & 1 & $0,21 \mathrm{~ns}$ & 1 & $8,50 *$ \\
\hline Dialac $(D I M)$ & 395 & $3,90 * *$ & 435 & $3,81 * *$ & 344 & $2,17 * *$ \\
\hline Idames $(A C)$ & 27 & $3,54 * *$ & 27 & $3,75 * *$ & 28 & $2,26 * *$ \\
\hline Mescon (MTD) & 11 & $4,48 * *$ & 11 & $17,46 * *$ & 11 & $5,94 * *$ \\
\hline Diaana $(D S)$ & 15 & $12,15 * *$ & 15 & $34,85 * *$ & 15 & $5,59 * *$ \\
\hline
\end{tabular}

(*) $\mathrm{P}<0,05 ;\left({ }^{* *}\right) \mathrm{P}<0,01$.

possível que vacas que iniciam a vida produtiva mais cedo tenham menores probabilidades de contrair mastite. Resultados nesse sentido foram observados por Kennedy et al. (1982), ao avaliarem a CCS em vacas Holsteins. Provavelmente, as variações crescentes da CCS e do ECS com o aumento da idade da vaca sejam conseqüência de possíveis interações animal $\times$ meio. Vacas com idades tardias ao primeiro parto refletem, principalmente, problemas de manejo reprodutivo e nutricional. Além desses problemas, essas 

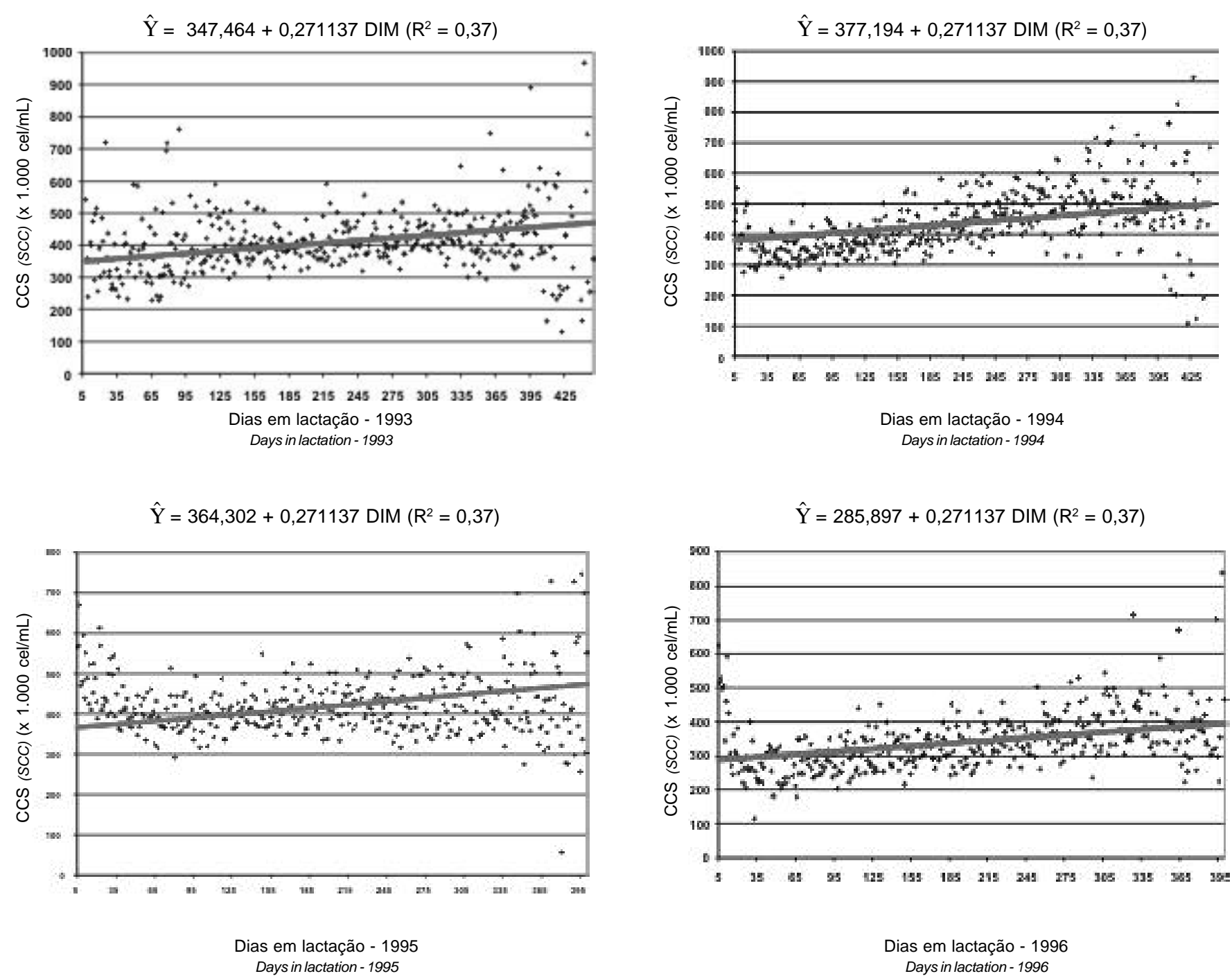

$\hat{\mathrm{Y}}=226,987+0,271137 \mathrm{DIM}\left(\mathrm{R}^{2}=0,37\right)$

$\hat{\mathrm{Y}}=270,411+0,271137 \mathrm{DIM}\left(R^{2}=0,37\right)$
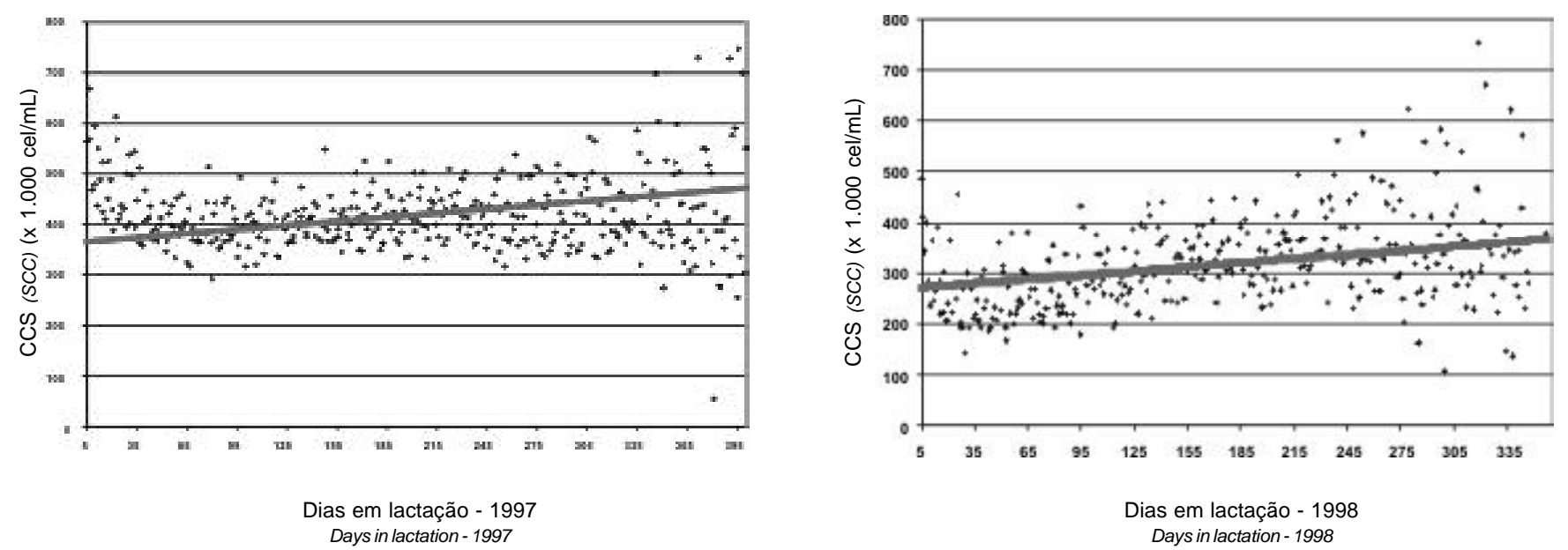

Figura 1 - Curvas de regressão ajustadas para efeito de ano de parto e média dos quadrados mínimos da contagem de células somáticas (CCS), segundo os dias em lactação, em vacas holandesas primíparas.

Figure 1 - Least square means for somatic cell count (SCC) regressed on days in lactation of first lactation Holstein cows, adjusted for calving year. 
$\hat{\mathrm{Y}}=3,5666+0,000968017 \mathrm{DIM}+0,000002584 \mathrm{DIM}^{2}\left(\mathrm{R}^{2}=0,77\right)$

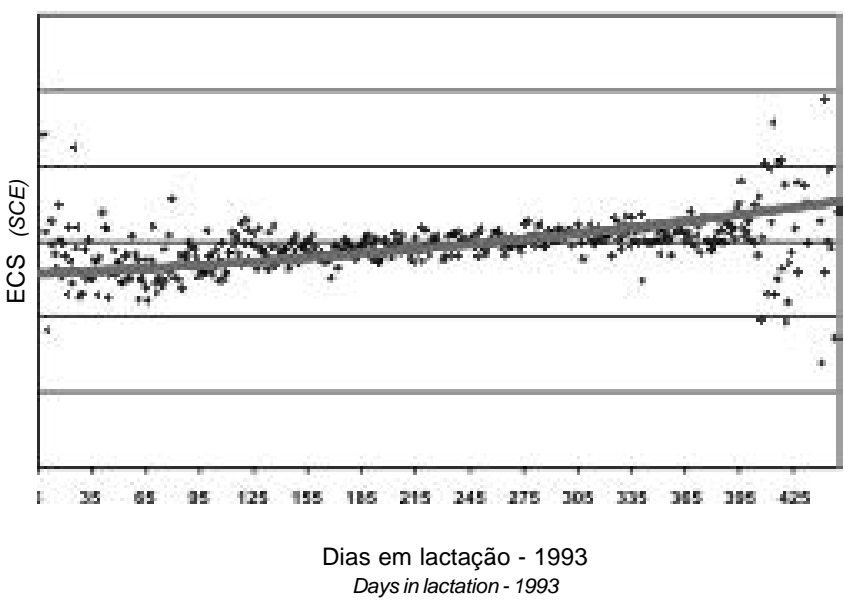

$\hat{\mathrm{Y}}=3,4802+0,000968017 \mathrm{DIM}+0,000002584 \mathrm{DIM}^{2}\left(\mathrm{R}^{2}=0,77\right)$

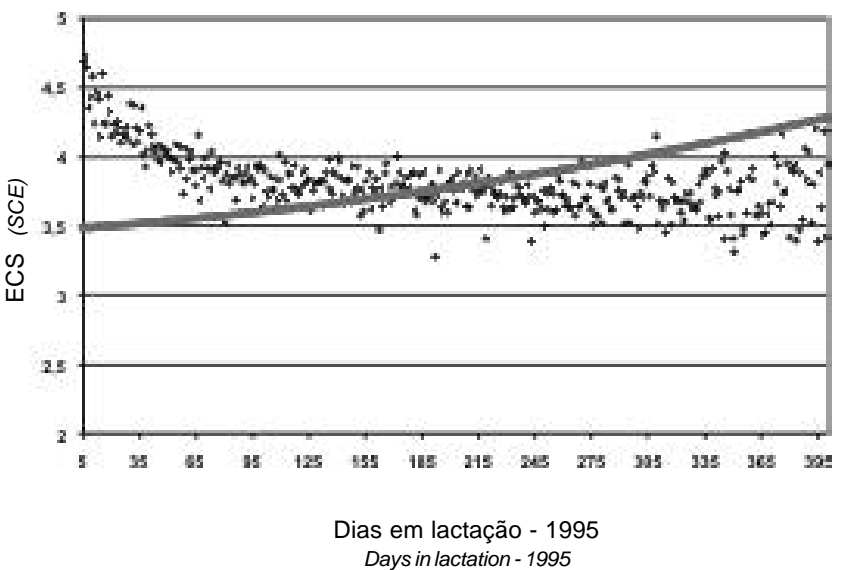

$\hat{\mathrm{Y}}=2,3764+0,000968017 \mathrm{DIM}+0,000002584 \mathrm{DIM}^{2}\left(\mathrm{R}^{2}=0,77\right)$

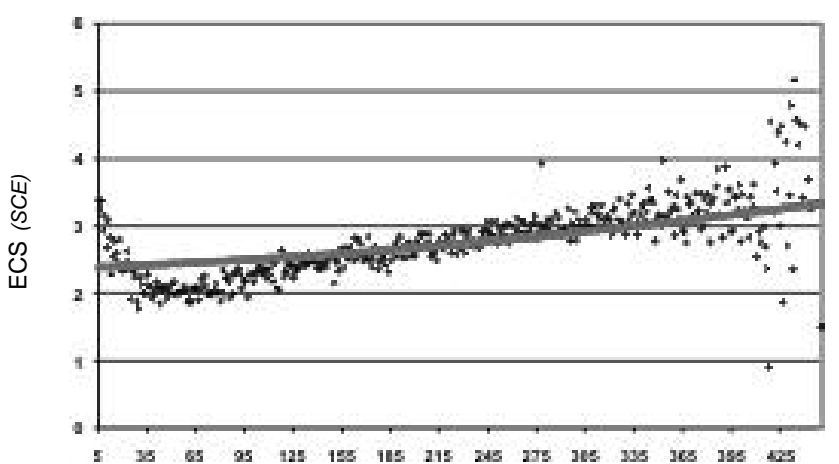

Dias em lactação - 1997

Days in lactation - 1997
$\hat{\mathrm{Y}}=3,7188+0,000968017 \mathrm{DIM}+0,000002584 \mathrm{DIM}^{2}\left(R^{2}=0,77\right)$

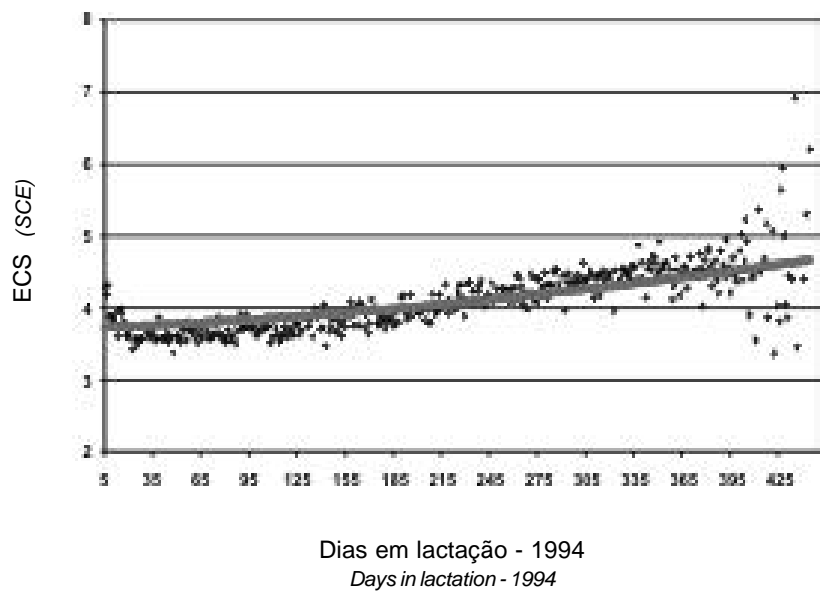

$\hat{\mathrm{Y}}=2,6729+0,000968017 \mathrm{DIM}+0,000002584 \mathrm{DIM}^{2}\left(\mathrm{R}^{2}=0,77\right)$

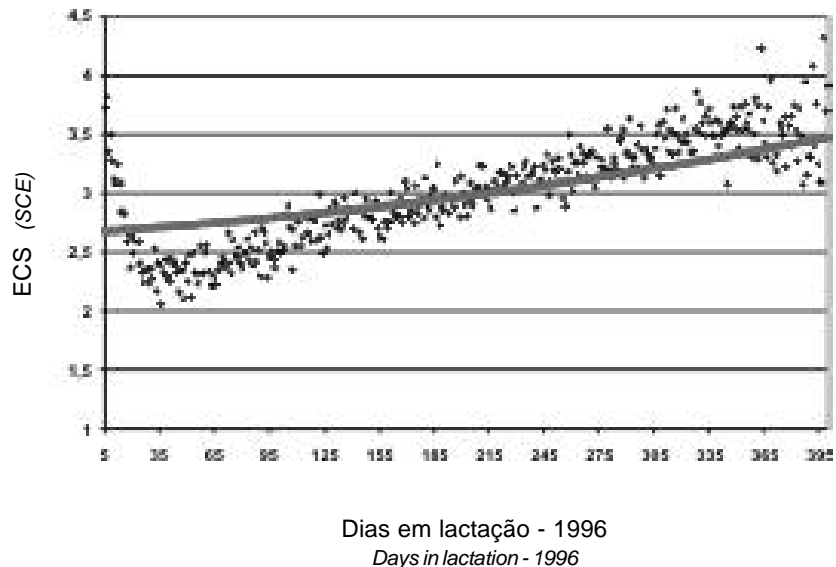

$\hat{\mathrm{Y}}=2,3873+0,000968017 \mathrm{DIM}+0,000002584 \mathrm{DIM}^{2}\left(\mathrm{R}^{2}=0,77\right)$

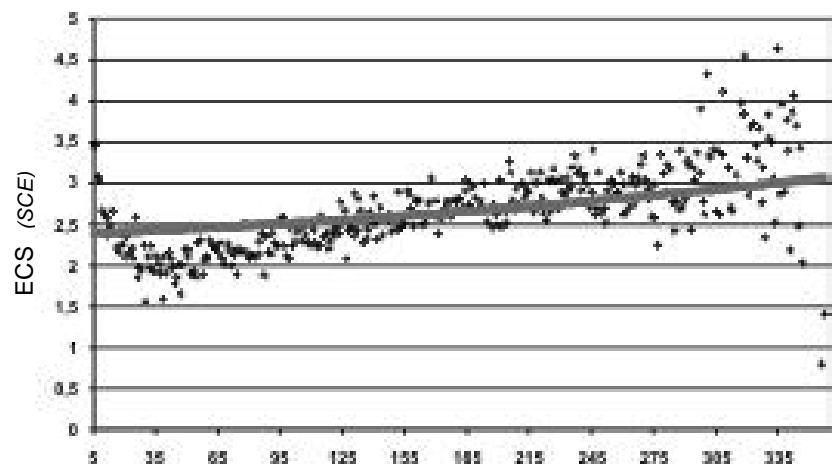

Dias em lactação - 1998 Days in lactation - 1998

Figura 2 - Curvas de regressão ajustadas para efeito de ano de parto e média dos quadrados mínimos do escore de células somáticas (ECS), segundo os dias em lactação, em vacas holandesas primíparas.

Figure 2 - Regression curve, adjusted to calving year effect and least square means of somatic cells score (SCE), by days in lactation in primiparous Holstein cows. 
Tabela 4 - Número de observações em função da idade da vaca ao parto Table 4 - Number of records for age of cow at calving

\begin{tabular}{|c|c|c|c|c|c|}
\hline $\begin{array}{l}\text { Idade da vaca (meses) } \\
\text { Age of cow (months) }\end{array}$ & $\begin{array}{l}\mathrm{N}^{\circ} \text { de observações } \\
\text { Number of records }\end{array}$ & $\%$ & $\begin{array}{l}\text { Idade da vaca(meses) } \\
\text { Age of cow (months) }\end{array}$ & $\begin{array}{l}\mathrm{N}^{\circ} \text { de observações } \\
\text { Number of records }\end{array}$ & $\%$ \\
\hline 20 & 460 & 0,27 & 31 & 7.170 & 4,24 \\
\hline 21 & 1.091 & 0,65 & 32 & 6.156 & 3,64 \\
\hline 22 & 3.438 & 2,03 & 33 & 5.060 & 2,99 \\
\hline 23 & 9.700 & 5,74 & 34 & 4.866 & 2,88 \\
\hline 24 & 16.214 & 9,59 & 35 & 4.613 & 2,73 \\
\hline 25 & 18.823 & 11,14 & 36 & 4.265 & 2,52 \\
\hline 26 & 19.262 & 11,40 & 37 & 3.976 & 2,35 \\
\hline 27 & 18.432 & 10,91 & 38 & 3.573 & 2,11 \\
\hline 28 & 15.319 & 9,06 & 39 & 3.337 & 1,97 \\
\hline 29 & 11.776 & 6,97 & 40 & 2.411 & 1,43 \\
\hline 30 & 9.051 & 5,36 & - & - & - \\
\hline
\end{tabular}
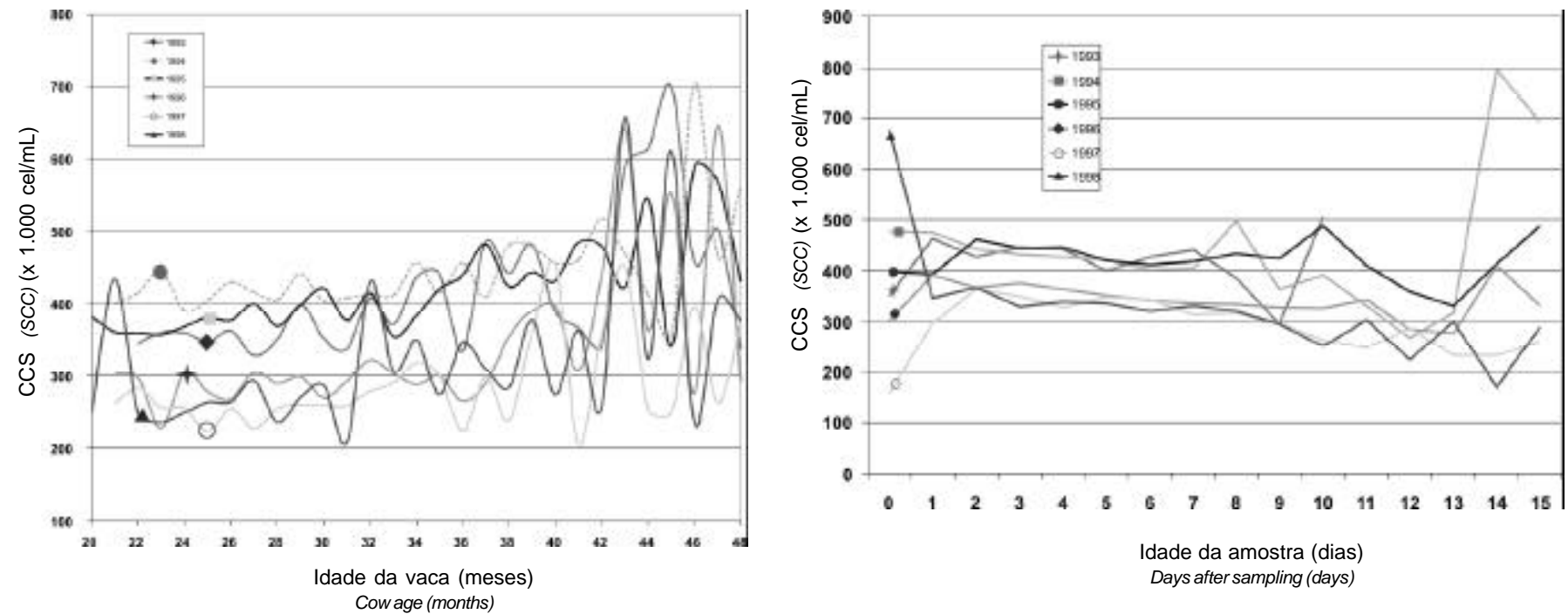

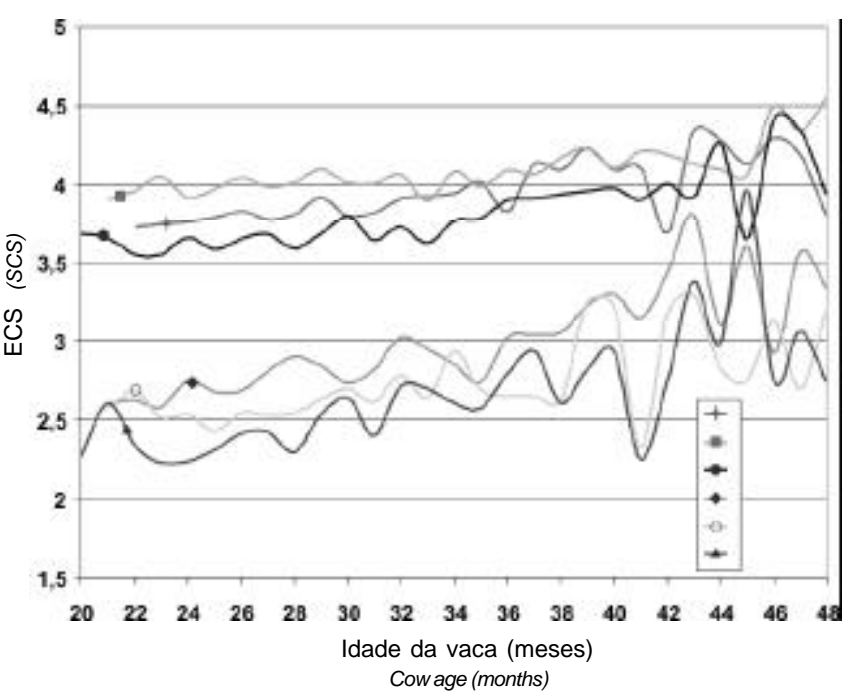

Figura 3 - Contagem de células somáticas (CCS) e escore de células somáticas (ECS) do leite de vacas holandesas primíparas de acordo com a idade da vaca.

Figure 3 - Somatic cell count (SCC) and somatic cell score (SCS) according to age at calving of first lactation Holstein cows.

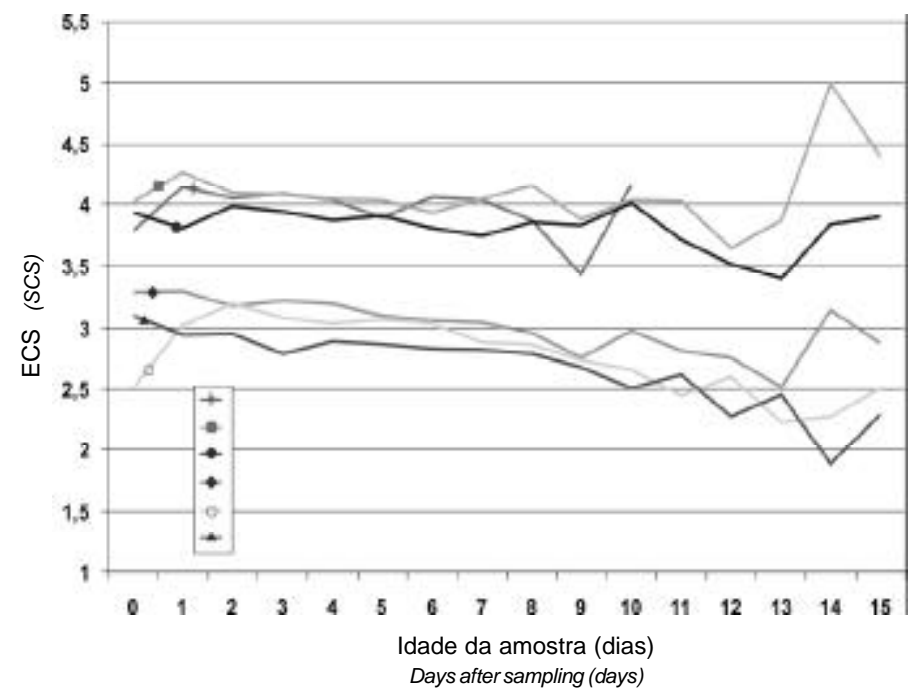

Figura 4 - Contagem de células somáticas (CCS) e escore de células somáticas (ECS) de vacas holandesas primíparas de acordo com a idade da amostra.

Figure 4 - Somatic cell count (SCC) and somatic cell score (SCS) of first lactation Holstein cows according to days after milk sampling. 
vacas ficam mais expostas ao ambiente e, com isso, aumentam a pré-disposição a infecções na glândula mamária.

Por serem características de baixa herdabilidade, conseqüentemente, fortemente influenciadas pelo ambiente, a CCS e o ECS estão sujeitos a grandes variações provocadas pelo mês em que as amostras foram obtidas. Os três primeiros anos (1993 a 1995) apresentaram variabilidade acentuada dos valores de CCS e ECS. Nos anos de 1993 e 1994, os maiores valores de CCS e ECS foram observados nos meses de abril (meio do outono) e os menores nos meses de agosto (final de inverno). $\mathrm{O}$ ano de 1995 foi totalmente atípico, com tendência inversa para os valores de CCS e ECS. Essas flutuações não tiveram nenhuma explicação clara, contudo, podem estar relacionadas aos ajustes na implantação do sistema de controle leiteiro, associados às mudanças nas práticas de manejo para controle da incidência de mastite. Nos anos seguintes (de 1996 a 1998), embora o mês de coleta tenha sido uma importante fonte de variação, afetando a CCS e ECS, as flutuações ao longo do ano foram bem mais estáveis. Além disso, nesses anos, houve marcante redução na quantidade de células somáticas no leite (Tabela 1).

A idade da amostra, correspondente ao intervalo entre o dia de coleta e a análise em laboratório, influenciou, significativamente $(\mathrm{P}<0,01)$ a CCS e o ECS (Tabelas 2 e 3 e Figura 4). De modo geral, houve tendência de redução nos valores de CCS e ECS à medida que aumentou a idade da amostra após coleta. Entretanto, as variações foram mais acentuadas nos dois primeiros dias após o sétimo dia de coleta. Kennedy et al. (1982), em lactações de vacas Holteins, observaram resultado semelhante quanto ao efeito signi- ficativo da idade da amostra sobre o ECS. Em geral, esses autores relataram ligeiro declínio nos três primeiros dias seguido de uma taxa de declínio gradual. Oito dias após a coleta, a redução na contagem de células somáticas variou de 28 a $36 \%$ conforme o estádio da lactação.

Nas Tabelas 5 e 6 são apresentadas as estimativas dos parâmetros de covariância para os efeitos aleatórios da CCS e do ECS, segundo o ano de parto da vaca. As correlações fenotípicas estimadas foram altas, com valores variando de 0,9591 a 0,9653, para CCS, e de 0,9632 a 0,9813, para ECS, o que denota estreita relação, para a mesma característica, de acordo com os dias em lactação. Os valores apresentados referem-se às correlações entre quaisquer dois dias em qualquer momento de lactação da vaca. Para calcular a correlação entre quaisquer outros dois dias de controle, tomou-se o valor entre dias consecutivos (Tabela 5) e elevou-se ao número de dias entre os controles $\left(\right.$ Ex: $\mathrm{dia}_{8} \rightarrow 0,9653^{4}=0,8683$ ou dia $_{5} / \mathrm{dia}_{35} \rightarrow 0,9653^{30}=$ 0,3466 ou dia $\left._{10} / \mathrm{dia}_{150} \rightarrow 0,9653^{140}=0,0071\right)$. Portanto, a correlação fenotípica decresceu para cada dia adicional entre observações (DIALAC). Resultado semelhante foi obtido por Norman et al. (1999) em lactações de vacas, no Canadá e nos Estados Unidos, utilizando um modelo estatístico autoregressive [ar(1)].

Os altos valores de correlações estimados entre dias consecutivos possibilita melhor estabelecimento e uso de práticas de rotina dentro do rebanho, pois sugere a manutenção ou não do dia-a-dia da fazenda para controle das células somáticas, visto que a mastite é ocasionada principalmente pela adoção de práticas higiênico-sanitárias inadequadas.

Tabela 5 - Estimativas dos parâmetros de covariância dos efeitos aleatórios para CCS segundo o ano de parto da vaca Table 5 - Covariance estimates of random effects for SCC by calving year of the cow

\begin{tabular}{lccccc}
\hline $\begin{array}{l}\text { Efeito } \\
\text { Effect }\end{array}$ & \multicolumn{3}{c}{$\begin{array}{c}\text { Ano de parto } \\
\text { Calving year }\end{array}$} \\
\cline { 2 - 6 } & 93 & 94 & 95 & 96 & 97 \\
\hline Região (region) & 14.626 & 11.750 & 11.883 & 17.390 & 21.125 \\
Vaca (cow) & 0,9653 & 0,9632 & 0,9591 & 0,9615 & 0,9605 \\
Resíduo (error) & 196.282 & 272.892 & 314.890 & 340.281 & 282.771 \\
\hline
\end{tabular}

Tabela 6 - Estimativas dos parâmetros de covariânciados efeitos aleatórios para ECS segundo o ano de parto da vaca Table 6 - Covariance estimates of random effects for SCS by calving year of the cow

\begin{tabular}{lcccrc}
\hline $\begin{array}{l}\text { Efeito } \\
\text { Effect }\end{array}$ & & \multicolumn{3}{c}{$\begin{array}{c}\text { Ano de parto } \\
\text { Calving year }\end{array}$} \\
\cline { 2 - 6 } & 93 & 94 & 95 & 96 & 97 \\
\hline Região (region) & 0,1179 & 0,1129 & 0,1554 & 0,3930 & 0,4349 \\
Vaca (cow) & 0,9632 & 0,9660 & 0,9763 & 0,9798 \\
Resíduo (error) & 1,0310 & 1,3161 & 1,7632 & 2,6662 & 2,6449 \\
\hline
\end{tabular}




\section{Conclusões}

As variáveis dias em lactação, idade da vaca ao parto, mês de controle da amostra e idade da amostra são importantes fontes de variação e devem ser consideradas na avaliação da CCS e do ECS.

Recomenda-se, dentro do possível, promover a primeira cobrição até os dois anos de idade, pois novilhas em idades mais avançadas são mais propensas a contrair infecções nas glândulas mamárias.

A quantidade de células somáticas no leite aumenta gradualmente à medida que a lactação avança do meio para o fim. A avaliação das amostras de leite deve ser feita entre um e sete dias (no máximo) depois da coleta.

Os altos valores estimados das correlações fenotípicas para CCS e ECS entre dias consecutivos denotaram estreita associação para a mesma característica, o que possibilita a adoção de práticas de manejo que possam contribuir para redução de mastites clínicas e/ou subclínicas.

\section{Literatura Citada}

ALI, A.K.A.; SHOOK, G.E. An optimum transformation for somatic cell concentration in milk. Journal of Dairy Science, v.63, n.3, p.487-90, 1980.

BRAMLEY, A.J.; CULLOR, J.S.; ERSKINE, R.J. et al. Current concepts of bovine mastitis. In: NATIONAL MASTITIS COUNCIL, 37., 1996, Madison. Proceedings... Madison: NMC, 1996. p.1-3.

COFFEY, E.M.; VINSON, W.E.; PEARSON, R.E. Potential of somatic cell concentration in milk as a sire selection criterion to reduce mastitis in dairy cattle. Journal of Dairy Science, v.69, n.8, p.2163-72, 1986.

COSTA, E.O.; RIBEIRO, A.R.; WATANABE, E.T. et al. Mastite sub-clínica: prejuízos causados e os custos de prevenção em propriedades leiteiras. Revista do Napgama, n.2, p.16-20, 1999

EMANUELSON, U.; PERSSON, E. Studies on somatic cell counts in milk from Swedish dairy cows. Acta Agriculturae Scandinavica, v.34, p.33-44, 1984.

EMANUELSON, U.; DANELL, B.; PHILIPSSON, J. Genetic parameters for clinical mastitis, somatic cell counts, and milk production estimated by multiple-trait restricted maximum likelihood. Journal of Dairy Science, v.71, n.2, p.467-76, 1988

HAILE-MARIAM, M.; GODDARD, M.E.; BOWMAN, P.J. Estimates of genetic parameters for daily somatic cell count of Australian dairy cattle. Journal of Dairy Science, v.84, n.5, p. 1255-64, 2001.

HERINGSTAD, B.; KLEMETSDAL, G.; RUANE, J. Selection for mastitis resistance in dairy cattle: a review with focus on the situation in the Nordic countries. Livestock Production Science, v.64, n.2/3, p.95-106, 2000.
HEUVEN, H.C.M.; BOVENHUIS, H.; POLITIEK, R.D. Inheritance of monthly somatic cell count and its genetic relationship with milk yield. Livestock Production Science, v.18, p.115, 1988.

HORTET, P.; BEAUDEAU, H.; SEEGERS, H. et al. Reduction in milk yield associated with somatic cell counts up to 600,000 cells/ml in French Holstein cows without clinical mastitis. Livestock Production Science, v.61, n.1, p.33-42, 1999.

KENNEDY, B.W.; SETHAR, M.S.; TONG, A.K.W. et al. Environmental factors influencing test-day somatics cell counts in Holsteins. Journal of Dairy Science, v.65, n.2, p.275-80, 1982.

LARRY SMITH, K.; HOGAN, J.S. Milk quality - A worldwide perspective. In: NATIONAL MASTITIS COUNCIL, 37., 1998, Madison. Proceedings... Madison: NMC, 1998. p.3-9.

LARRY SMITH, K.; TODHUNTER, D.A.; SCHOENBERGER, P.S. Environmental mastitis: cause, prevalence, prevention. Journal of Dairy Science, v.68, n.6, p.1531-53, 1985.

MRODE, R.A.; SWANSON, G.T.J. Genetic and statistical properties of somatic cell count and its suitability as an indirect means of reducing the incidence of mastitis in dairy cattle. Animal Breeding Abstracts, v.64, p.847-57, 1996.

NORMAN, H.D.; VANRADEN, P.M.; WRIGHT, J.R. et al. Mathematical representations of correlations among yield traits and somatic cell score on test day. Journal Dairy Science, v.82, n.10, p.2205-11, 1999.

PHILIPSSON J.; RAL, G.; BERGLUND, B. Somatic cell count as a selection criterion for mastitis resistance in dairy cattle. Livestock Production Science, v.41, n.3, p.195-200, 1995.

PÖSÖ, J.; MÄNTYSAARI, E.A. Relationships between clinical mastitis, somatic cell score and production for the first three lactations of Finnish Ayrshire. Journal of Dairy Science, v.79, n.7, p.1284-91, 1996.

RUPP, R.; BOICHARD, D. Genetic parameters for clinical mastitis, somatic cell score, production, udder type traits, and milking ease in first lactation Holsteins. Journal of Dairy Science, v.82, n.10, p.2198-204, 1999

RUPP, R.; BOICHARD, D. Relationship of early first lactation somatic cell count with risk of subsequent first clinical mastitis. Livestock Production Science, v.62, n.2, p.169-180, 2000.

STATISTICAL ANALYSIS SYSTEM - SAS. SAS Companion for the Microsoft Windows Environment. Version 8, Cary: 2000. (CD-ROM).

SHOOK, G.; RUEGG, P. Geometric mean somatic cell counts: what they are; what they do. In: NATIONAL MASTITIS COUNCIL, 38., 1999, Arlington. Proceedings... Arlington: NMC, 1999. p. $93-100$

SHOOK, G.E. A linear scale for scoring somatic cell count. In ANNUAL MEETING OF AMERICAN DAIRY SCIENCE ASSOCIATION, 1982, Pennsylvania. Proceedings... Pennsylvania State University, University Park, 1982a. p.1-7.

SHOOK, G.E. Approaches to summarizing somatic cell count which improve interpretability. In: NATIONAL MASTITIS COUNCIL, 21., 1982, Washington. Proceedings... Washington, D.C.: 1982b. p.150-66.

ST-PIERRE, N.R. Invited review: Integrating quantitative findings from multiple studies using mixed model methodology. Journal Dairy Science, v.84, n.4, p.741-55, 2001

Recebido: 05/09/05 Aprovado: 18/08/06 